\title{
UNA AMISTAD QUE TRASCIENDE EN EL TIEMPO
}

\author{
Mariana Mould de Pease ${ }^{1}$ \\ ... Son muchas las ocasiones en que hemos pasado tiempo juntos, en continua \\ discusión de nuestros estudios, en ejercicio de una vinculación personal \\ que su generosidad ha hecho rica y nutrida... Pease (2000)
}

Este texto presenta algunos rasgos y hechos de la amistad entre John V. Murra y Franklin Pease G.Y., como colegas así como de maestro a seguidor que han contribuido a dar forma a los estudios andinos en el Perú así como las características resaltantes de sus respectivas personalidades que los llevaron a convertirse en prestigiosos investigadores y profesores. Además, refiero cómo John introdujo en el Perú y Bolivia -respectivamente- la noción de conservación del patrimonio documental en proceso de destrucción así como la recuperación del patrimonio etnológico robado.

John V. Murra (1916-2006) y Franklin Pease G.Y. (1939-1999) fueron dos hombres muy diferentes entre sí por sus orígenes familiares así como por sus respectivas maneras de hacerse andinistas. En la década de 1960 John pasó bastante tiempo en el Perú, especialmente en Lima, mientras decidía el lugar para establecerse como profesor universitario y Franklin se propuso ganarse su amistad, mediante las conversaciones sobre el Tahuantinsuyu y la necesidad de trabajar la documentación administrativa colonial, que así se hicieron más frecuentes. En estas reuniones también se hablaba de las variables étnicas de la comida y sus ingredientes así como de su preparación; de las respectivas relaciones familiares; de la política peruana y/o estadounidense; de los avatares del viajar y las dificultades de John para conciliar el sueño en aviones, automóviles y buses así como en hoteles ruidosos. Esta era una situación desconocida para Franklin, ya que era inmune al ruido perturbador, debido a una severa pérdida auditiva que lo acompañaba desde la niñez. John -siempre impaciente-repetía lo que había expuesto cuando Franklin no le había oído bien.

El compromiso de John con la continuidad y vigencia de la vida andina desde tiempos prehispánicos hasta su presente que expuso por primera vez en Lima en 1958 con motivo del Congreso de Historia Militar hizo que se conocieran y desarrollaran esa amistad especializada, al margen de estas aparentemente grandes diferencias personales. La vida social que John llevaba era también una forma de vivir hablando de los hombres y las mujeres andinas dentro de las sociedades boliviana, chilena, ecuatoriana así como peruana -retándolas desde dentro- así como presentando a estas personas en Buenos Aires, Barcelona y cualquier parte del mundo. En Lima más de una vez lo vimos sentirse muy incómodo ya fuera en una conferencia o en una conversación porque sus oyentes e interlocutores le ponían límites al mundo andino para avanzar hacia una impuesta occidentalización. Las cartas intercambiadas entre sí -que ambos conservaron-dan testimonio que hacia 1968 ya tenían una permanente conversación epistolar sobre la reciprocidad, el manejo de los recursos, la complementariedad ecológica y humana que se racionalizaba a través de la articulación de la antropología, la arqueología y la historia en los Andes en su relación ya sea con la administración universitaria o con la vida peruana en general. $\mathrm{La}$ publicación en 1975 de Formaciones ... con los artículos dispersos de John reunidos por Franklin, es el principal eje temático de esta correspondencia ya que casi de inmediato comenzaron a organizar la segunda edición en forma de libro de estas separatas. Valga la siguiente carta fechada el 9 de junio de 1988, para entender mejor esta amistad que ya otorga continuidad a la comprensión del Perú como país andino:

Querido Franklin,

Me alegro tener noticia tuya, particularmente saber que sigues tan activo... el correo es muy

$1 \quad$ Calle Santa Isabel 343, Miraflores, Lima, Perú. curaca@terra.com.pe 
lento, casi 2 semanas por carta. Ya estarás de regreso de Arica y allá verás que mal pueden ir las cosas, aún si tenemos una Facultad de Estudios Andinos ... He tenido comunicación de Jorge [Hidalgo]; ojalá pueda aceptar la beca de la John Carter Brown ...

No tengo ninguna noticia más desde $\mathrm{B}$ [aires] $\mathrm{A}$ [ires] pero supongo que los planes para ir allá el segundo semestre (agosto a nov[iembre]), siguen en pie. Esto me permitirá verificar cualquier cosas que haga falta de los yndios del Emp[erador] en el archivo de allá. No se que haré después del semestre en $\mathrm{B}$ [uenos] $\mathrm{A}$ [ires] -si tengo alguien de confianza en la casa [en Ithaca] quizás puedo detenerme lejos del invierno... también depende si mi hermana logra salir por un rato de Rumania- los inviernos allá se han vuelto intolerables para la gente de edad -2 horas de luz y calefacción al día...

Por el momento vamos a olvidarnos de una nueva edición de Formaciones ... no hay prisa

Pasando ahora a tu visita a EEUU. Yo estuve en Maryland a principios de abril por unos días y me hizo una excelente impresión. El [Saúl] Sosnowski es hombre de empresa y sabe movilizar el público -yo hablé de la coca en la historia y de otras cosas en reuniones más pequeñas. La Bibli[oteca] del Congreso no queda tan cerca pero sí es accesible ... Si estoy en Ithaca en la época, estás bienvenido en cualquier momento. Si no, la casa será alquilada.

No, no tengo la carta de J. de Cáceres.

Sí, creo que una selección del juicio entre los obispados será suficiente ... el no. 10, el motín no me parece tener interés fuera del hecho que tales cosas ocurren en la zona e indican la cantidad y presencia y de influencia de españoles... Creo que podemos eliminarlo-se publicará en alguna publicación de la región. Si falta algo del AGI, tengo allí jóvenes con los cuales trabajé en 1986 y quienes se ocuparían de buscar páginas en particular o cualquier otro detalle $\mathrm{q}[\mathrm{ue}]$ nos falte. No creo que habrá dificultad de obtener permiso de Thierry [Seignes] para publicar cosas que el ha encontrado. El 'catálogo' q[ue] el ha hecho de AGN de B[aires] A[ires], le parece el más completa q[ue] he visto.

Estaré aquí hasta fines de julio y voy a re-leer la visita entera para remozar mi conocimiento para ver q[ue] digo, Te felicito por todas tus obligaciones, nuevas y por venir ...

Tuyo, John
En agosto de 1998 durante el homenaje a John llevado a cabo en el salón de grados de la UNMSM, Franklin anunció que ya Murra había aceptado que la Universidad Católica editara sus artículos sobre el mundo andino dando así continuidad a su libro de 1975. El fallecimiento de Franklin en 1999 parecía haber dilatado indefinidamente esta publicación.

La presentación de Nispa Ninchis. Conversaciones con John Murra en mayo del 2000 trajo a John a Lima por última vez y así durante un cálido almuerzo en casa de Freda Y. Wolf de Romero sus expresivos ojos negros volvieron a brillar unos instantes para decirme que hiciera posible esta publicación. Unos días después apareció Heather Letchman -con Ana María Soldi- y comenzó la transformación de esa carpeta en el libro que apareció en el 2002, con la participación activa Carlos Contreras del Instituto de Estudios Peruanos que John había contribuido a formar en 1964 y que coincidimos que debía titularse: El Mundo Andino. Población, Medio Ambiente y Economía.

Conversaciones con John Murra capturó para siempre el habla internacionalizadora así como los intereses profundamente humanos de nuestro homenajeado que ahora sus editores complementan-desde Chile- invitándonos a hacernos presentes en esta feliz iniciativa. Además, este libro ha documentado cómo John tanto en su trabajo de archivo como de campo enseñaba también lineamientos básicos de defensa y conservación del patrimonio cultural. En el primer caso, está su afirmación:

la gente de Lima no entendió el programa de la UNESCO para microfilmar documentos antiguos y lo que hicieron es darle a copiar la Visita de Huаписо porque no le iban a dar nada que no estuviera publicado. Entonces yo que sabía de eso empecé a predicar (2000:112).

El segundo es la devolución de los tejidos ceremoniales robados del ayllu de Quruma (o Coroma), en Potosí con su participación y por eso John nos dice: "Ganamos, pero como siempre son victorias tan marginales en comparación con el desastre que está ocurriendo" (2000:128-129).

John es el hombre más cosmopolita que Franklin y yo conocimos y tratamos en nuestra vida, obviamente, nos deslumbró ya que habiendo tenido muchas opciones había optado por hacerse andinista. Él era selectivo con su amistad ya que no tenía paciencia y era cuestión de congeniar con él en base a un 
compromiso sincero y trabajador con la antropología, la arqueología, la historia andina que lo llevaba por el mundo. Se sabía persona interesante así como que su presencia prestigiaba a sus anfitriones, podía abrirse y darse en la exposición y la conversación tanto como escuchar... cuando quería.

El firme compromiso de John con su vocación de andinista universal así como de maestro interlocutor tenía una continuidad que lo llevó a participar y también organizar reuniones académicas comenzando por buscar la financiación económica, puesto que siempre tuvo plena conciencia que el dinero es un recurso limitado. Así el seminario en torno al Lago Titicaca y el control andino de diversos pisos ecológicos que dirigió con Luis G. Lumbreras en agosto de 1973, era parte de esta secuencia. Puesto que Franklin estuvo entre los becarios peruanos, nos fuimos a La Paz. Luego de las reuniones académicas y disfrutar de la hospitalidad de las autoridades paceñas pasamos en automóvil con John, Ana María Soldi y Elías Mujica a Potosí para consultar el archivo que dirigía Gunnar Mendoza quien nos dio todas las facilidades para localizar la indispensable documentación referida a los reinos lacustres y la verticalidad andina. Luego del primer día de trabajo John -inquieto y pragmático- decidió que para aprovechar al máximo los recursos invertidos en este viaje él y Elías, aún un joven estudiante de arqueología, debían ir al archivo de Sucre por lo que nos recogerían en el viaje de regreso a La Paz. Franklin-siempre coordinando con John como se puede verificar en la correspondencia mutuamente intercambiada- consultó el archivo de Sucre en 1983 para el proyecto de ambos de editar la más completa documentación posible sobre los reinos lacustres, en seguimiento a la carta del visitador Garcí Díez de San Miguel que había publicado en 1965. Se reunieron en torno a esta documentación colonial para ordenarla para su publicación -por última vez- en agosto de 1998.

El cáncer pancreático terminal que aquejó a mi esposo Franklin, a fines de 1998, dejó trunco este trabajo y las copias de estos documentos así como las respectivas fichas están en nuestra casa miraflorina como parte de la "Colección Franklin Pease G.Y. para la historia andina del Perú", que estoy poniendo en valor en la Biblioteca Nacional. En 1985 Shozo Masuda, Craig, Morris e Izumi Shimada organizaron la Conferencia "Ecología y Civilización Andina, una perspectiva interdisciplinaria sobre la complementariedad ecológica andina”. Esta era una sutil manera de homenajear a John reuniendo a especialistas de cinco países en torno a su propuesta del "Archipiélago Vertical". John nos dio allí una lección magistral sobre cómo dar continuidad al mundo andino al "re visitar el Archipiélago Vertical" (Murra en Masuda et al. 1985:3-13).

Durante esa semana en que convivimos en aislamiento voluntario para hablar permanentemente del mundo andino, su manejo continuado del medio ambiente y recursos naturales así como de su economía, su organización social y política, John mostró excepcionales dotes de respeto por las peculiaridades de los demás, una vitalidad para hacerse presente en los distintos grupos que se formaban cuando concluía la diaria sesión de trabajo, así como un buen humor a prueba de las conversaciones repetitivas.

Habiéndose acogido a la jubilación temprana en 1982 de la Universidad de Cornell, organizaba cuidadosamente su tercera edad para ir a hablar -a donde fuera invitado- de la Guerra Civil Española, de lo andino, así como de los derechos y patrimonios culturales de las más diversas minorías que él conocía muy bien al haber nacido judío en Ucrania y ser inmigrante en los EE.UU. Se sabía siempre bien recibido.

La sutil discriminación que ocurre en el Perú -incluso en el ambiente académico- la percibía de inmediato y buscaba desarticularla ya fuese abiertamente o de manera exquisita, como cuando se enteró que a algunos distinguidos intelectuales limeños les molestaba que Toribio Mejía Xesspe hubiera seguido publicando de manera conjunta con Julio C. Tello-fallecido en 1945 y considerado el padre de la arqueología peruana- en base a sus apuntes y libretas de campo. En la conversación continua que John tenía con Franklin nos contó que estas personas incluso habían tratado de inducir a la familia Tello a enjuiciar a Mejía cuando en 1979 apareció el segundo volumen de Paracas, editado por la Universidad Nacional Mayor de San Marcos/UNMSM. Entonces Franklin -sin dar explicaciones- publicó en Histórica de julio de 1983 el testamento del doctor Julio César Tello y Rojas -redactado en su lecho de muerte- en que Mejía y Rebeca Carrión Cachot son referidos como sus colaboradores inmediatos que mejor conocen su trabajo y se alude a la UNMSM como la institución que puede publicar sus estudios e investigaciones que quedaban pendientes. Mejía-fallecido el 2 de noviembre de 1983- que se había hecho arqueólogo 
al lado de Tello y como él era vástago de una familia de campesinos andinos.

La libertad y la independencia que tuvo John en su tercera edad le sirvió para seguir consolidando los estudios andinos interdisciplinarios tanto fuera como dentro de los Andes. El Programa de Estudios Andinos de la Escuela de Post Grado de la Pontificia Universidad Católica del Perú es también resultante de las conversaciones de esos años como se puede verificar en la correspondencia entre Franklin y John. En esta correspondencia también ha quedado consignado cómo después de su temprana jubilación John dispuso de su biblioteca así como de sus archivos para que fueran preservados en diversos repositorios bibliográficos y documentales por lo que es tarea todavía pendiente dar continuidad a este legado mediante la complementariedad en el trabajo.

\section{Referencias Citadas}

Castro, V., C. Aldunate y J. Hidalgo, editores

2000 Nispa Ninchis. Conversaciones con John Murra. Instituto de Estudios Peruanos e Institute of Andean Research, Lima.

Masuda, Sh., I. Shimada y C. Morris, editores 1985 Andean Ecology and Civilization. An Interdisciplinary Perspective on Andean Ecological Complementarity. University of Tokyo Press, Tokio.

\section{Murra, J.V.}

1975 Formaciones Económicas y Políticas del Mundo Andino. Instituto de Estudios Peruanos, Lima.
2002 El Mundo Andino. Población, Medio Ambiente y Economía. Instituto de Estudios Peruanos, Pontificia Universidad Católica del Perú, Lima.

Pease G.Y., F.

2000 Discurso de Homenaje. En Nispa Ninchis. Conversaciones con John Murra, editado por V. Castro, C. Aldunate y J. Hidalgo. Instituto de Estudios Andinos e Institute of Andean Research, Lima.

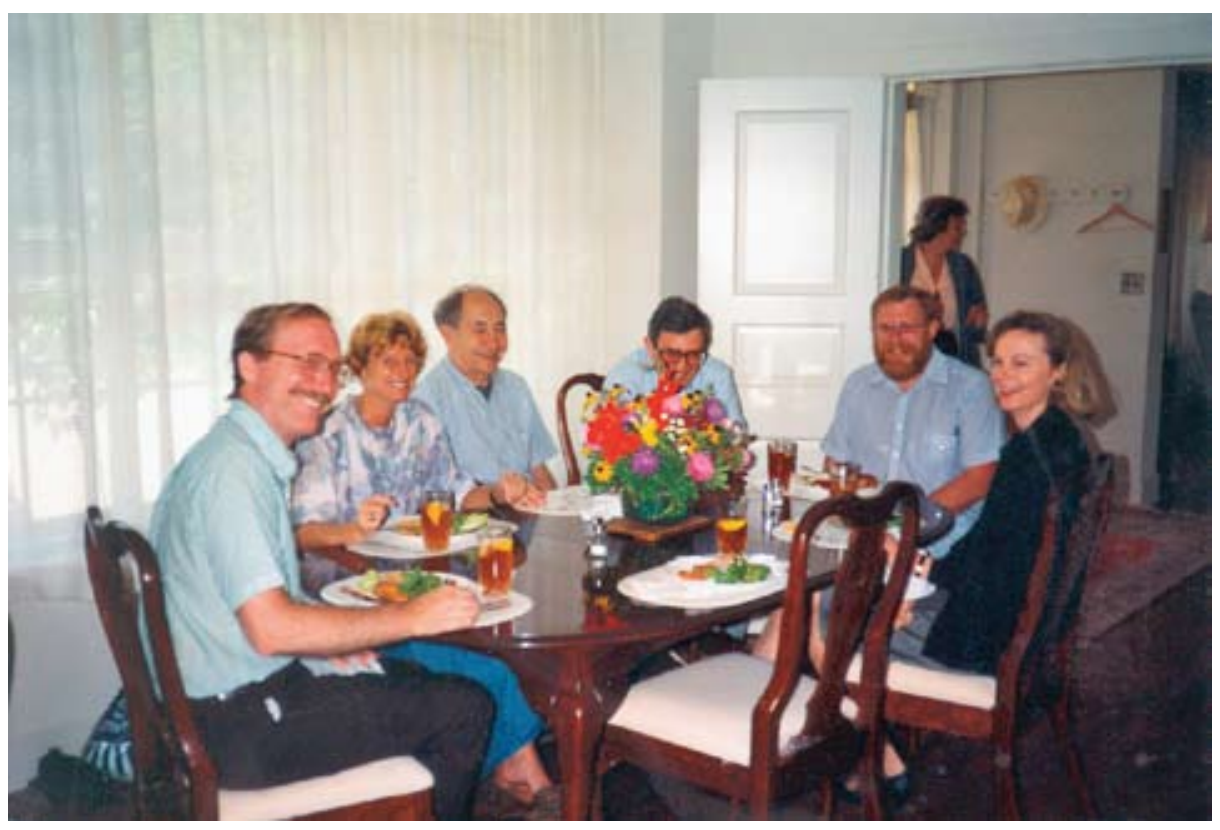


Una amistad que trasciende en el tiempo

37

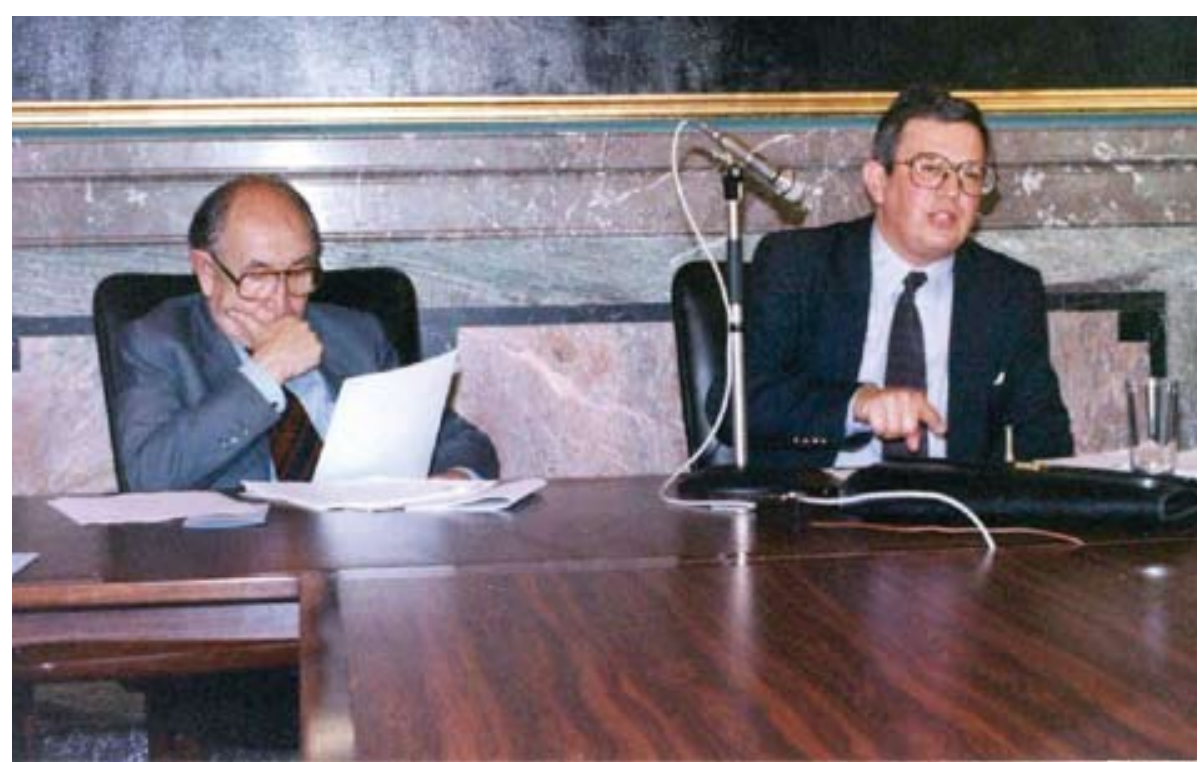

CORNELL UNIVERSITY

ITHACA, N. Y. 14850

Department of Anthropology

McGraw Hall.

Luceers

hi querido FrauklinLa primeria uoticia fue sa gran prérdida. En estos nounectors tan graves pode todos hds, os maudo mi abraz. ftakenual, ui tolidaridad en la pena.

Se de nuastras couversacioner lo nucleo que rapresentaba on padre en on fer privado - y appero qua encortrará algín aliento en saber que no e tá fólo.

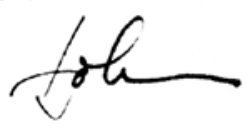



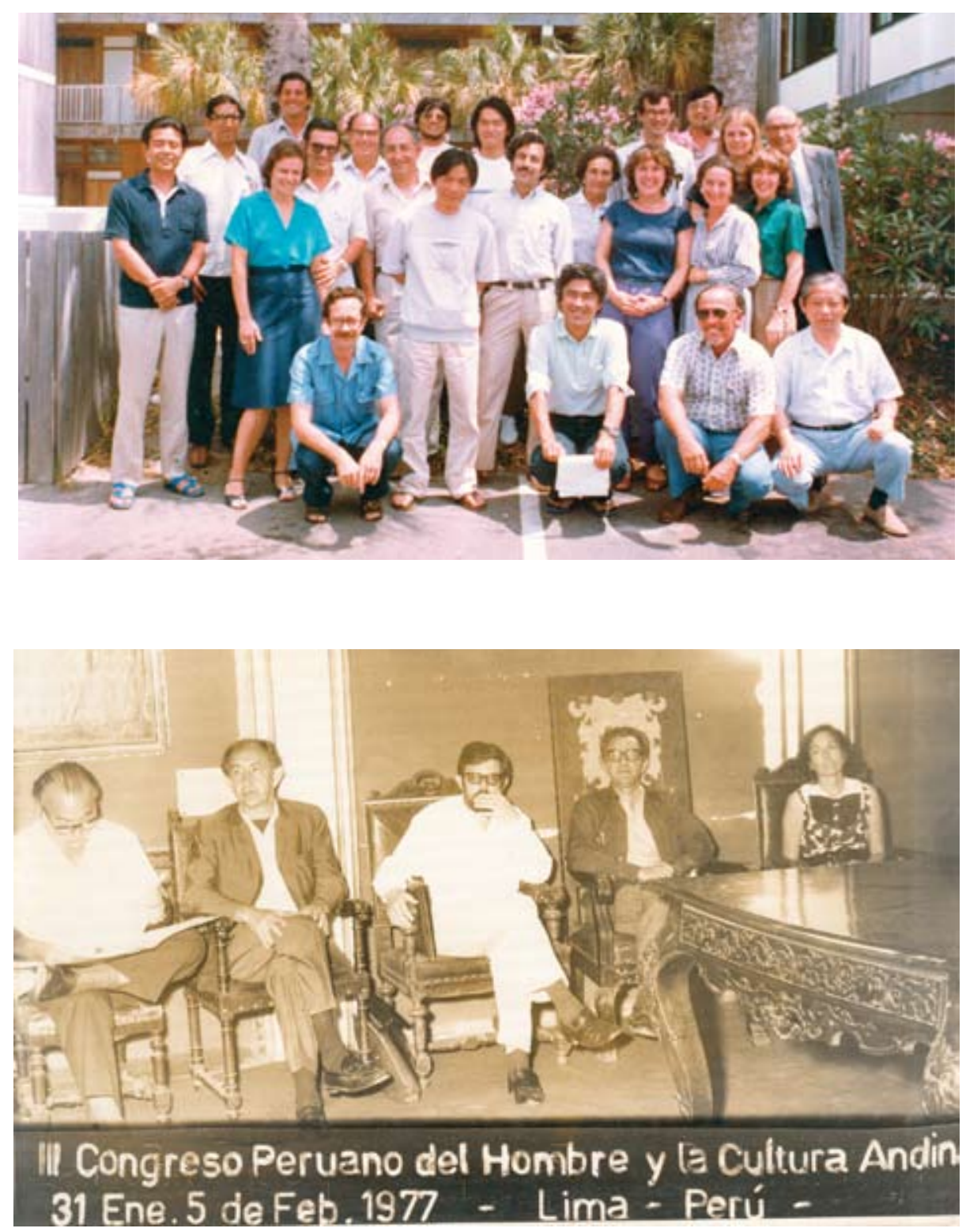